\title{
Análise da qualidade técnica de estudos de impacto ambiental em ambientes de Mata Atlântica de Santa Catarina: abordagem faunística
}

\author{
Marinez Scherer \\ Universidade Federal de Santa Catarina, Centro de Filosofia e Ciências Humanas \\ Departamento de Geociências, Campus Universitário \\ CEP 88.040-970, Florianópolis - SC, Brasil \\ marinezscherer@gmail.com
}

Submetido em 02/02/2011

Aceito para publicação em 23/08/2011

\section{Resumo}

Alterações nos componentes de um ecossistema levam a modificações nas interações ecológicas, sendo algumas vezes irreversíveis ou de grande magnitude, podendo ocasionar a perda de biodiversidade. Para controlar as alterações sobre os ecossistemas existem políticas públicas e instrumentos de controle e licenciamento dos usos e atividades humanas. Nesse trabalho, realizou-se uma análise crítica de Relatórios de Impacto Ambiental dos aspectos referentes à fauna de cinco Estudos de Impacto Ambiental (EIAs) realizados no contexto do Bioma Mata Atlântica. Os resultados identificaram carências, tais como: (i) ausência de informação sobre invertebrados terrestres; (ii) ausência da identificação de áreas de reprodução e alimentação; (iii) identificação superficial de fenômenos de migração e de aspectos comportamentais; (iv) caracterização superficial das interações ecológicas; (v) ausência da identificação da estrutura das comunidades presentes e espécies-chave; e (vi) ausência da identificação de bioindicadores. A maioria dos estudos de impacto ambiental não realiza um diagnóstico do meio biótico suficientemente adequado para subsidiar a posterior avaliação de impactos, e a avaliação de impactos ambientais não relaciona as interações ecológicas com as intervenções humanas resultantes do empreendimento/ atividade analisado. Conclui-se, dessa forma, que o EIA é um instrumento que ainda pode ser bastante melhorado em relação às questões ecológicas analisadas, visando subsidiar o processo decisório.

Palavras-chave: Bioindicadores, EIA, Fauna, Interações Ecológicas

\section{Abstract}

Analysis of the technical quality of environmental impact studies done on the Atlantic Rain Forest of Santa Catarina: a faunistic approach. Alterations in components of an ecosystem might modify ecological interactions, which are sometimes irreversible, and could cause a loss in biodiversity. In order to control ecosystem alterations caused by human activity, public policies and control tools, such as environmental licenses, have been developed. This work carried out a critical analysis of aspects related to the fauna from five Environmental Impact Assessments (EIAs) prepared in the context of the Atlantic Rain Forest biome. The following deficiencies were found in the studies analyzed: (i) absence of information about terrestrial invertebrates; (ii) absence of identification of reproduction and feeding areas; (iii) superficial identification of migration and behavior aspects; (iv) superficial characterization of ecological interactions; (v) absence of identification of community structure and key-species; and (vi) absence of the identification of bioindicators. The EIAs did not adequately diagnose 
the biological system in order to point out subsequent impacts. Similarly, the environmental impact evaluations did not relate ecological interactions with the human activities that were planned in the development proposals. Therefore the ecological aspects of the EIAs in Santa Catarina could be (and should be) substantially improved in order to provide more accurate data during the decision-making process.

Key words: Ecological interactions, Environmental Impact Assessment, Indicators, Fauna

\section{Introdução}

Um dos objetivos do desenvolvimento sustentável pressupõe, entre outras coisas, a conservação biológica (SACHS, 1986; CICIN-SAIN, 1993). Sendo assim, instrumentos que se propõem a auxiliar na gestão desse desenvolvimento e dos ambientes naturais devem incorporar elementos da teoria ecológica em suas análises.

O planeta Terra é constituído de diferentes biomas (tundra, floresta tropical, savana, entre outros), sendo cada um deles um grande biossistema regional caracterizado por um tipo principal de vegetação ou outro aspecto identificador de paisagem (ODUM, 1988). Um bioma também é definido por características climáticas, sendo constituído de diferentes ecossistemas que, por sua vez, são formados por comunidades abrangendo um conjunto de fatores abióticos e bióticos de uma determinada área, formando uma unidade funcional.

Nenhuma espécie, ou população de uma espécie, ocorre sozinha; é sempre parte de um conjunto de populações que compartilham uma mesma área, formando comunidades (KREBS, 1985). A comunidade biótica interage entre si e com ambiente físico de maneira que cada fator influencia as propriedades do outro, sendo cada um necessário à manutenção dessas relações (ODUM, 1988; PULLIN, 2004). Dessa maneira, as interações entre os fatores bióticos e abióticos regulam as condições de sobrevivência das populações que compõem a comunidade de um ecossistema. As espécies dependem de outras espécies e do meio para alimentação, abrigo, reprodução.

Por consequência, a conservação de espécies e das populações, comunidades e ecossistemas, depende da conservação das interações ecológicas que incluem, entre outras, competição, predação, parasitismo, simbiose e ainda as interações entre os seres vivos e os fatores abióticos, tais como água, temperatura, luz, salinidade, solo, entre outros (PULLIN, 2004).
Quando um ou mais dos fatores é modificado, por razões externas ou internas ao sistema, as interações entre as populações que formam a comunidade e aquelas existentes entre a comunidade e o meio físico acabam por serem modificadas também. Uma vez que essas transformações ocorrem de maneira diferente nos diferentes grupos taxonômicos (HOCKEY; CURTIS, 2009), o conhecimento de todos os grupos presentes em um ecossistema é muito importante.

Essas alterações na estrutura do ecossistema podem ser pequenas, sendo que o próprio ecossistema se adapta às novas condições; ou ainda serem de grande magnitude, de maneira que as interações existentes nesse ecossistema sofram alterações profundas levando ao colapso do sistema e, em última análise, do bioma no qual está inserido. A grandeza dessas alterações e suas consequências dependem do tipo de ecossistema, de grau de maturidade, isto é, se são mais ou menos complexos, se apresentam maior ou menor número de interações ecológicas; assim como do tipo de transformação imputada a esse ambiente.

O ser humano tem a capacidade de modificar o ambiente, levando a alterações significativas dos ecossistemas. Tais alterações geram consequências negativas ao meio ambiente e ao Homem, justificando ações gerenciais que impeçam ou minimizem essas modificações.

O bioma Mata Atlântica é constituído por vegetação litorânea (restinga), manguezais e floresta ombrófila (ASSIS et al., 1994) e ocupa grande parte da zona costeira do Brasil. Esse bioma apresenta particularidades agravantes no que tange as modificações do ambiente por ser uma área de alta densidade populacional e grande concentração de usos e atividades humanas urbanização, introdução de espécies exóticas, indústrias, turismo, entre outros impactos (KAY; ALDER, 1999; SCHERER, 2001). Segundo Ribeiro et al. (2009), do 
bioma Mata Atlântica original restam entre 11\% a 16\% da cobertura vegetal original, levando-se em conta áreas maiores que 100ha de floresta primária, assim como pequenos fragmentos e vegetação secundária em regeneração.

A preocupação com as alterações de origem antrópica nos ecossistemas, e em especial nos ecossistemas inseridos no bioma Mata Atlântica, tem induzido ao desenvolvimento de políticas públicas para a conservação desses ambientes no Brasil. No entanto, é imperativo que as políticas públicas e seus instrumentos de implantação levem em consideração a complexidade das interações ecológicas para que sejam eficientes em alcançar a conservação das comunidades e dos ecossistemas.

Os Estudos de Impacto Ambiental (EIA) e as respectivas Avaliações de Impacto Ambiental (AIA), que constituem parte integrante dos EIAs, estão entre os instrumentos mais importantes e mais utilizados no Brasil para o planejamento e prevenção das alterações antrópicas sobre os ecossistemas. O estudo de impacto ambiental é previsto na Política Nacional de Meio Ambiente (PNMA), determinada pela Lei federal $\mathrm{n}^{\mathrm{0}} 6.938$ de 31 de agosto de 1981. Segundo a PNMA, o EIA e seu relatório (RIMA) são instrumentos válidos e obrigatórios em processos de licenciamento de empreendimentos de grande porte. A resolução do Conselho Nacional de Meio Ambiente (CONAMA) n ${ }^{\circ}$ 001/86, de 21 de janeiro de 1986, regulamentou esses estudos, definindo critérios básicos para a exigência do EIA no licenciamento de projetos de atividades modificadoras do meio ambiente. Segundo esta resolução, o EIA deverá conter um diagnóstico sócio-ambiental das áreas de influência do empreendimento, com ênfase na área de implantação do projeto. Ressalta-se que o conteúdo do estudo deve ser sempre determinado por um Termo de Referência avalizado pelo órgão ambiental competente que, em Santa Catarina, costuma ser a Fundação de Meio Ambiente - FATMA.

A partir dos dados levantados no diagnóstico, a equipe do estudo deverá proceder ao processo de avaliação dos impactos ambientais. Assim, o maior objetivo de um estudo de impactos ambientais é identificar e avaliar os impactos negativos de um empreendimento ou atividade, visando à adoção de medidas mitigadoras, com o propósito de evitá-los ou minimizá-los (MOTA, 2003).

A avaliação dos impactos ambientais passa por três passos fundamentais: (i) análise do problema identificando os possíveis impactos diretos, indiretos e cumulativos; (ii) mensuração de sua significância determinando magnitude, extensão, efeito, custos; e (iii) determinação de ações mitigadoras e ou compensatórias. Assim, os critérios de avaliação ambiental passam pela determinação de critérios qualitativos e quantitativos (SÁNCHEZ, 2006).

Como forma de avaliação de impactos sobre a biota, muitos autores sugerem o uso de indicadores biológicos e/ou físicos (BARROS, 2001; PETRUCIO et al., 2005; NEVES; BEMVENUTI, 2006; SANFORD et al., 2009). Mudanças na abundância ou no comportamento de organismos da fauna ou flora, ou ainda em variáveis físico-químicas, podem indicar mudanças ambientais causadas por ações antrópicas. Barros (2001), Neves e Bemvenuti (2006) e Blankensteyn (2006), por exemplo, sugerem a observação do comportamento e abundância do caranguejo Maria Farinha (Ocypode quadrata) como um instrumento para ajudar na determinação de mudanças ambientais em praias, que poderiam implicar em consequentes alterações das relações ecológicas daquela comunidade.

Petrucio et al. (2005) sugerem o estudo de variáveis físicas, químicas e/ou microbiológicas como maneira de identificar alterações em ambientes aquáticos originadas por ações antrópicas. Já Sanford et al. (2009) sugerem a observação de formigas para determinar alterações ambientais.

O conhecimento das chamadas espécies-chave em uma comunidade também é considerado muito importante para a conservação. As espécies-chave são aquelas cuja remoção (ou extinção) levará a grandes alterações na estrutura de uma comunidade (LANA, 2003; TOWNSEND et al., 2006). Assim, a determinação dessas espécies e do impacto que tal atividade terá sobre a abundância e distribuição dessas espécies é um fator importante na determinação da magnitude do impacto. 
Uma vez conhecidos os bioindicadores, as espécieschave e os processos ecológicos do ecossistema com o qual se trabalha, torna-se mais fácil inferir os impactos ambientais causados por determinadas intervenções humanas. Na medida em que se verifiquem mudanças ou até mesmo o desaparecimento de organismos ou grupos de organismos, ou na qualidade física, química ou geológica do ambiente, é possível que o uso do espaço natural esteja alterando significativamente as condições ambientais da área, levando muitas vezes à degradação ambiental e perda da biodiversidade.

Underwood e Chapman (1995), no entanto, fazem a ressalva de que se deve ter muito cuidado com as informações obtidas através da observação de mudanças ambientais ou de indicadores. Essas transformações muitas vezes podem ser parte da variabilidade natural daquele ecossistema e não terem sido causadas por atividades externas. Assim, esses autores recomendam que, para se poder imputar à atividade antrópica as mudanças significativas observadas nos bioindicadores deveriam ser feitas amostragens Beyond BACI (before and after control impacts), ou seja, ter dados da variável dependente, replicados temporalmente e espacialmente, de antes e de depois do suposto impacto em áreas controle e em áreas supostamente impactadas. Com esses dados pode-se inferir com mais confiabilidade se uma alteração observada foi causada pela ação humana. Sánchez (2006) corrobora a idéia, ressaltando a importância da validade estatística dos dados para comparação entre a situação da área antes de depois da alteração causada.

Apesar da literatura especializada já indicar quais são os tipos de estudos e de informações necessários para o planejamento adequado das atividades humanas modificadoras dos ambientes naturais, existem diversos indícios de que a situação atual da qualidade ambiental do bioma Mata Atlântica em Santa Catarina continua sendo deteriorada. Dessa forma, esse estudo propõe a hipótese geral de que os Estudos de Impactos Ambientais realizados em Santa Catarina carecem de um aprofundamento no âmbito da ciência ecológica, suficiente para subsidiar adequadamente os processos decisórios sobre o licenciamento ambiental de empreendimentos e atividades potencialmente impactantes.

\section{Objetivos e hipóteses de trabalho}

O objetivo desse trabalho é analisar a qualidade técnica de estudos de impacto ambiental no bioma Mata Atlântica catarinense a fim de verificar a contribuição desses instrumentos à conservação dos ecossistemas, em especial à fauna. Diversos trabalhos indicam que estudos de impacto ambiental são instrumentos deficientes de apoio à tomada de decisão (FAIRWEATHER, 1989; 1994; BRASIL, 2004). Assim, se propõe que esta indicação também seja válida no estado de Santa Catarina. Dessa forma, as seguintes hipóteses de trabalho são propostas:

a) se encontrará um número maior de estudos de impacto ambiental que não realizam um diagnóstico do meio biótico suficientemente completo para subsidiar a posterior avaliação de impactos, do que aqueles que assim o fazem;

b) a avaliação de impactos ambientais, obrigatoriamente presentes nos estudos de impacto ambiental, não relaciona as interações ecológicas, eventualmente descritas no diagnóstico, com as intervenções humanas resultantes do empreendimento/atividade analisado.

\section{Material e Métodos}

De acordo com a Resolução 01/2006 do Conselho Estadual de Meio Ambiente de Santa Catarina (CONSEMA), existem diferentes estudos ambientais válidos para um processo de licenciamento (ex: Estudo de Impacto Ambiental - EIA; Estudo Ambiental Simplificado - EAS e Relatório Ambiental Prévio - RAP) e todos eles exigem avaliação de impactos ambientais, em diferentes níveis de aprofundamento, de acordo com a magnitude do uso ou atividade.

Neste trabalho foram analisados aspectos do diagnóstico biótico relativo à fauna, presentes nos Estudos de Impacto Ambiental; assim como a avaliação de impacto ambiental descrita nesses estudos, também referentes à fauna.

Utilizou-se Estudos de Impacto Ambiental e seus Relatórios de Impacto Ambiental (EIA/RIMA) por se tratarem dos estudos mais complexos exigidos em um processo de licenciamento. Assim, é nos EIA/RIMAs 
onde se esperaria encontrar diagnósticos bióticos mais completos, assim como avaliações de impactos mais criteriosas.

Uma vez que, somente os Relatórios de Impacto Ambiental estão disponíveis à consulta pública na biblioteca da FATMA, como objeto de estudos, analisouse os RIMAs com respeito à zona costeira e bioma Mata Atlântica catarinense e que se encontram disponíveis para consulta pública na biblioteca da Fundação de Meio Ambiente do Estado de Santa Catarina (FATMA). Analisaram-se estudos entre os anos de 2002 e 2009 para retratar o atual estado da arte desse tipo de estudo. Estas datas foram escolhidas por serem as datas dos estudos mais recentes disponíveis na biblioteca da FATMA.

Salienta-se que um RIMA é parte integrante de um EIA, constituindo uma síntese do EIA e devendo ser apresentado à comunidade numa forma de fácil entendimento. Assim, a ausência de nomes científicos em um RIMA, por exemplo, não significa que o estudo não considere essa nomenclatura. No entanto, apesar do formato mais amigável de um RIMA, as informações constantes devem ser igualmente válidas e suficientes, além de apresentar os impactos e suas medidas mitigadoras de forma abrangente.

Pela quantidade de estudos disponíveis e existentes na biblioteca da FATMA, aliado ao tempo estabelecido para realizar o trabalho, optou-se por selecionar cinco estudos considerados representativos, tomando-se o cuidado de eleger estudos realizados por empresas diferentes, na tentativa de refletir estilos e métodos diversificados de diagnóstico e análise. Uma vez que o nome da empresa e o nome do empreendimento são irrelevantes para análise aqui proposta, os mesmos foram omitidos, sendo indicado o tipo de empreendimento estudado e o município onde ele foi proposto. Os estudos analisados foram os seguintes:

a) Loteamento residencial - Imbituba;

b) Parque de Inovação Tecnológica - Florianópolis;

c) Estaleiro - Navegantes;

d) Central de Tratamento e Disposição de Resíduos Sólidos - Içara;

e) Complexo Turístico-Residencial - Governador Celso Ramos.
Em cada um dos estudos procedeu-se a análise dos seguintes itens:

1) Indicadores de diagnóstico do meio biótico-fauna

- Metodologia utilizada para o diagnóstico;

- Grupos taxonômicos analisados;

- Caracterização de relações ecológicas existentes na área de estudo e seu entorno;

- Bioindicadores e espécies-chave apresentados;

- Identificação de espécies endêmicas, raras e ameaçadas de extinção.

2) Aspectos referentes à Avaliação de Impacto Ambiental

- Tipos de impactos à fauna descritos;

- Medidas mitigadoras e compensatórias indicadas e relacionadas aos impactos sobre a fauna;

A partir da análise dos estudos foram estruturados quadros de descrição e comparação utilizando-se as variáveis analisadas, que permitiram testar as hipóteses propostas e elaborar as discussões e conclusões desse trabalho.

\section{Resultados}

\section{Indicadores de diagnóstico do meio biótico-fauna}

A análise dos dados obtidos demonstra que os estudos apresentam dados quantitativos na forma de listagem de espécies. A presença de invertebrados nessas listagens somente aparece quando se trata de indivíduos aquáticos, não havendo citação de invertebrados terrestres em nenhum dos estudos (Tabela 1). Dois estudos não apresentam a listagem de espécies no seu RIMA, mas as análises indicam que foi realizado um levantamento da fauna cuja listagem resultante encontra-se provavelmente no EIA, não disponível ao público.

As listagens de espécies apresentadas nos estudos possuem pouca ou nenhuma relação das mesmas com o meio físico. Já as descrições de relações intra-específicas não foram identificadas nos estudos analisados (Tabela 2). 
Espécies bioindicadoras não são citadas, ainda que um dos estudos estabeleça uma relação entre uma determinada espécie e a qualidade do ambiente aquático. Da mesma maneira, não são citadas por nenhum dos estudos as espécies-chave, a estrutura da comunidade estudada e o papel dessas espécies nessa estrutura (Tabela 2).

Com relação à identificação das espécies raras, endêmicas ou ameaçadas de extinção, somente dois estudos dedicam um item específico para esse parâmetro. Os outros estudos fazem apenas menção às espécies consideradas críticas no corpo do texto, sendo que um deles não avalia a eventual existência de espécies raras, endêmicas ou ameaçadas de extinção (Tabela 2).

\section{Aspectos referentes à Avaliação de Impacto Ambiental}

A avaliação de impactos (AIA) apresentada pelos estudos demonstrou ser bastante superficial no que se refere aos impactos à fauna. Dois estudos não citam os impactos diretamente à fauna, ainda que considerem certas atividades inerentes do empreendimento como levemente impactantes (Tabela 3). De maneira geral, os impactos mais recorrentemente apontados foram: perda ou alteração de habitat e afugentamento da fauna.

TABELA 1: Grupos taxonômicos apresentados pelos estudos.

\begin{tabular}{|c|c|c|c|c|c|}
\hline $\begin{array}{c}\text { Grupos } \\
\text { Taxonômicos }\end{array}$ & Estudo 1 & Estudo 2 & Estudo 3 & Estudo 4 & Estudo 5 \\
\hline Metodologia & $\begin{array}{l}\text { Campo e revisão } \\
\text { bibliográfica }\end{array}$ & \multirow{8}{*}{$\begin{array}{l}\text { Não descreve } \\
\text { metodologia e } \\
\text { também não cita } \\
\text { quais espécies } \\
\text { foram encontradas } \\
\text { na área de estudo } \\
\text { e nem suas } \\
\text { abundâncias }\end{array}$} & $\begin{array}{l}\text { Descreve apenas } \\
\text { para a fauna } \\
\text { aquática }\end{array}$ & \multirow{8}{*}{$\begin{array}{l}\text { Não cita } \\
\text { metodologia e } \\
\text { também não cita } \\
\text { quais espécies } \\
\text { foram encontradas } \\
\text { na área de } \\
\text { estudo nem suas } \\
\text { abundâncias, mas } \\
\text { afirma que os } \\
\text { grupos de avifauna } \\
\text { e mastofauna } \\
\text { foram estudados }\end{array}$} & $\begin{array}{l}\text { Descreve apenas } \\
\text { para } \\
\text { a fauna aquática }\end{array}$ \\
\hline $\begin{array}{l}\text { Invertebrados } \\
\text { Terrestres }\end{array}$ & Sem citações & & Sem citações & & Sem citações \\
\hline $\begin{array}{l}\text { Invertebrados } \\
\text { Aquáticos (quando } \\
\text { houver corpo } \\
\text { hídrico na área do } \\
\text { empreendimento) }\end{array}$ & $\begin{array}{l}\text { Sem citações } \\
\text { (banhado na área) }\end{array}$ & & $\begin{array}{l}\text { Listagem } \\
\text { espécies } \\
\text { (estuário) }\end{array}$ & & $\begin{array}{l}\text { Listagem de } \\
\text { espécies } \\
\text { (ambiente } \\
\text { marinho) }\end{array}$ \\
\hline $\begin{array}{l}\text { Peixes (quando } \\
\text { houver corpo } \\
\text { hídrico na área do } \\
\text { empreendimento) }\end{array}$ & $\begin{array}{l}\text { Citação de duas } \\
\text { espécies, sendo } \\
\text { uma como } \\
\text { primeiro registro } \\
\text { para a região } \\
\text { (banhado na área) }\end{array}$ & & $\begin{array}{l}\text { Listagem } \\
\text { espécies }\end{array}$ & & Sem citações \\
\hline Anfíbios & $\begin{array}{l}\text { Listagem de } \\
\text { espécies }\end{array}$ & & $\begin{array}{l}\text { Listagem de } \\
\text { espécies }\end{array}$ & & $\begin{array}{l}\text { Listagem de } \\
\text { espécies }\end{array}$ \\
\hline Répteis & $\begin{array}{l}\text { Listagem de } \\
\text { espécies }\end{array}$ & & $\begin{array}{l}\text { Listagem de } \\
\text { espécies }\end{array}$ & & $\begin{array}{l}\text { Listagem de } \\
\text { espécies com } \\
\text { ênfase em } \\
\text { quelônios } \\
\end{array}$ \\
\hline Aves & $\begin{array}{l}\text { Listagem de } \\
\text { espécies }\end{array}$ & & $\begin{array}{l}\text { Listagem de } \\
\text { espécies }\end{array}$ & & $\begin{array}{l}\text { Listagem de } \\
\text { espécies }\end{array}$ \\
\hline Mamíferos & $\begin{array}{l}\text { Listagem de } \\
\text { espécies }\end{array}$ & & $\begin{array}{l}\text { Listagem de } \\
\text { espécies }\end{array}$ & & $\begin{array}{l}\text { Listagem de } \\
\text { espécies com } \\
\text { ênfase em } \\
\text { cetáceos } \\
\end{array}$ \\
\hline
\end{tabular}

Fonte: Elaboração própria com base nos estudos avaliados. 
TABELA 2: Parâmetros ecológicos analisados pelos estudos.

\begin{tabular}{|c|c|c|c|c|c|}
\hline $\begin{array}{l}\text { Parâmetros } \\
\text { Ecológicos } \\
\text { Analisados }\end{array}$ & Estudo 1 & Estudo 2 & Estudo 3 & Estudo 4 & Estudo 5 \\
\hline $\begin{array}{l}\text { Identificação } \\
\text { das relações } \\
\text { ecológicas e/ } \\
\text { ou relação } \\
\text { espécies-meio }\end{array}$ & $\begin{array}{l}\text { Não são identificas } \\
\text { interações } \\
\text { ecológicas. }\end{array}$ & \begin{tabular}{|l|} 
Apresenta dados de \\
densidade, diversidade \\
e faz relações com a \\
estrutura da comunidade. \\
Relaciona presença das \\
espécies com o meio.
\end{tabular} & $\begin{array}{l}\text { Relaciona } \\
\text { presença das } \\
\text { espécies com o } \\
\text { meio e área de } \\
\text { criadouro para } \\
\text { peixes. }\end{array}$ & $\begin{array}{l}\text { Não são } \\
\text { identificas } \\
\text { interações } \\
\text { ecológicas. }\end{array}$ & $\begin{array}{l}\text { Observações } \\
\text { sazonais para } \\
\text { alguns grupos } \\
\text { taxonômicos. }\end{array}$ \\
\hline $\begin{array}{l}\text { Bioindicadores } \\
\text { e espécies- } \\
\text { chave } \\
\text { apresentados }\end{array}$ & $\begin{array}{l}\text { Não identifica } \\
\text { bioindicadores ou } \\
\text { espécies-chave }\end{array}$ & $\begin{array}{l}\text { Não identifica } \\
\text { bioindicadores ou } \\
\text { espécies-chave }\end{array}$ & $\begin{array}{l}\text { Indica algumas } \\
\text { espécies aquáticas } \\
\text { como dependentes } \\
\text { da qualidade do } \\
\text { meio }\end{array}$ & $\begin{array}{l}\text { Não identifica } \\
\text { bioindicadores } \\
\text { ou espécies- } \\
\text { chave }\end{array}$ & $\begin{array}{l}\text { Não identifica } \\
\text { bioindicadores ou } \\
\text { espécies-chave }\end{array}$ \\
\hline $\begin{array}{l}\text { Identificação } \\
\text { de espécies } \\
\text { endêmicas, } \\
\text { raras e } \\
\text { ameaçadas de } \\
\text { extinção. }\end{array}$ & $\begin{array}{l}\text { Cita que a área se } \\
\text { encontra dentro } \\
\text { dos limites } \\
\text { de ocorrência } \\
\text { de Liolaemus } \\
\text { occipitalis - } \\
\text { espécie vulnerável }\end{array}$ & $\begin{array}{l}\text { Sem destaque no texto, } \\
\text { mas identifica a área } \\
\text { como de provável } \\
\text { ocorrência de Caiman } \\
\text { latilostris (jacaré de } \\
\text { papo amarelo) e Lontra } \\
\text { longicaudis (lontra). }{ }^{1}\end{array}$ & $\begin{array}{l}\text { Sem destaque, } \\
\text { citando espécies } \\
\text { vulneráveis no } \\
\text { corpo do texto. }\end{array}$ & Não identifica & $\begin{array}{l}\text { Cita que não } \\
\text { existem essas } \\
\text { espécies na área de } \\
\text { estudo. No entanto, } \\
\text { cita a provável } \\
\text { presença de } \\
\text { Caiman latilostris } \\
\text { (jacaré do papo } \\
\text { amarelo) })^{1} \text {. }\end{array}$ \\
\hline
\end{tabular}

Fonte: Elaboração própria com base nos estudos avaliados.

TABELA 3: Avaliação de Impactos apresentada pelos estudos.

\begin{tabular}{|c|c|c|c|c|c|}
\hline $\begin{array}{c}\text { Avaliação } \\
\text { de Impactos } \\
\text { Ambientais }\end{array}$ & Estudo 1 & Estudo 2 & Estudo 3 & Estudo 4 & Estudo 5 \\
\hline $\begin{array}{l}\text { Impactos } \\
\text { à fauna } \\
\text { descritos }\end{array}$ & $\begin{array}{l}\text { - Perda de habitat } \\
\text { - Contaminação de } \\
\text { habitat } \\
\text { - Obstáculos para o } \\
\text { fluxo da fauna } \\
\text { - Afugentamento de } \\
\text { fauna }\end{array}$ & $\begin{array}{l}\text { Não identifica } \\
\text { explicitamente os } \\
\text { impactos para a } \\
\text { fauna. } \\
\text { Considera que certas } \\
\text { ações tem impacto } \\
\text { leve para a fauna } \\
\text { local. O texto cita } \\
\text { ainda, para Caiman } \\
\text { latilostris: perda } \\
\text { de habitat, e para } \\
\text { Lontra longicaudis: } \\
\text { perturbação do } \\
\text { habitat. }\end{array}$ & $\begin{array}{l}\text { - Perda de habitat } \\
\text { - Afugentamento } \\
\text { de fauna } \\
\text { - Alteração de } \\
\text { qualidade } \\
\text { ambiental } \\
\text { - Redução da } \\
\text { abundância dos } \\
\text { organismos } \\
\text { aquáticos } \\
\text { - Supressão da } \\
\text { fauna bentônica } \\
\text { - Contaminação do } \\
\text { meio aquático }\end{array}$ & \begin{tabular}{|l|} 
Não identifica \\
explicitamente \\
os impactos para \\
a fauna. \\
No entanto \\
considera que \\
as certas ações \\
tem impacto \\
insignificantes \\
para a fauna \\
local. Demais \\
atividades \\
não foram \\
consideradas \\
como \\
impactantes.
\end{tabular} & $\begin{array}{l}\text { - Afugentamento } \\
\text { de fauna terrestre } \\
\text { e avifauna } \\
\text { - Alteração de } \\
\text { habitats para } \\
\text { organismos } \\
\text { aquáticos } \\
\text { - Captura de } \\
\text { ictiofauna } \\
\text { - Danos } \\
\text { fisiológicos } \\
\text { à fauna por } \\
\text { derrame de óleo. }\end{array}$ \\
\hline
\end{tabular}




\begin{tabular}{|c|c|c|c|c|c|}
\hline $\begin{array}{l}\text { Medidas } \\
\text { mitigadoras } \\
\text { e compen- } \\
\text { satórias } \\
\text { apontadas }\end{array}$ & $\begin{array}{l}\text { - Recuperação e } \\
\text { preservação de áreas } \\
\text { verdes } \\
\text { - Salvamento e } \\
\text { monitoramento da } \\
\text { fauna } \\
\text { - Gestão de resíduos } \\
\text { sólidos e tratamento } \\
\text { de efluentes } \\
\text { - Uso de materiais } \\
\text { que permitam aos } \\
\text { animais identificarem } \\
\text { obstáculos } \\
\text { - Sinalização das vias } \\
\text { de tráfego } \\
\text { - Iluminação indireta } \\
\text { - Treinamento e } \\
\text { educação ambiental } \\
\text { para funcionários }\end{array}$ & $\begin{array}{l}\text {-Zoneamento das } \\
\text { lagoas } \\
\text { - Educação ambiental } \\
\text { sobre o Caiman } \\
\text { latilostris: } \\
\text { - Criação de habitat } \\
\text { aquático } \\
\text { - Instalação de } \\
\text { redutores de } \\
\text { velocidade nas vias } \\
\text { de acesso } \\
\text { - Colonização dos } \\
\text { lagos com espécies } \\
\text { nativas e/ou } \\
\text { exóticas }\end{array}$ & $\begin{array}{l}\text { - Recuperação } \\
\text { e preservação } \\
\text { de áreas verdes } \\
\text { como corredores } \\
\text { ecológicos } \\
\text { - Monitoramento } \\
\text { da fauna aquática } \\
\text { - Monitoramento } \\
\text { dos ruídos } \\
\text { - Treinamento } \\
\text { e educação } \\
\text { ambiental para } \\
\text { funcionários } \\
\text { - Sistema de } \\
\text { tratamento } \\
\text { das águas da } \\
\text { drenagem }\end{array}$ & $\begin{array}{l}\text { Não cita } \\
\text { medidas de } \\
\text { mitigação de } \\
\text { impactos para a } \\
\text { fauna. Menciona } \\
\text { apenas } \\
\text { recuperação de } \\
\text { áreas degradadas } \\
\text { como forma de } \\
\text { manutenção de } \\
\text { habitat }\end{array}$ & $\begin{array}{l}\text { - Comunicação } \\
\text { e educação } \\
\text { ambiental } \\
\text { - Monitoramento } \\
\text { da biota terrestre } \\
\text { e aquática } \\
\text { - Resgate da fauna } \\
\text { - Monitoramento } \\
\text { da drenagem } \\
\text { - Controle dos } \\
\text { ruídos } \\
\text { - Gestão dos } \\
\text { resíduos sólidos } \\
\text { e efluentes. }\end{array}$ \\
\hline
\end{tabular}

Fonte: Elaboração Própria com base nos estudos avaliados.

Dentre as medidas mitigadoras e/ou compensatórias as mais citadas são: recuperação e preservação de áreas verdes; educação ambiental e treinamento para os funcionários dos empreendimentos; resgate de fauna; monitoramento de fauna e gestão de resíduos sólidos e efluentes (Tabela 3 ).

\section{Discussão}

A partir dos dados coletados pode-se inferir que os Estudos de Impacto Ambiental apresentam deficiências no diagnóstico faunístico e na avaliação de impactos ambientais. Essa observação é corroborada por outras publicações que analisaram estudos semelhantes, tais como Brasil (2004) e Fairweather (1989; 1994).

Segundo publicação do Ministério Público Federal que objetivou avaliar as carências em estudos de impacto ambiental (BRASIL, 2004), os principais problemas no tocante ao diagnóstico faunístico nesses estudos são:

a) ausência de dados sobre organismos de determinados grupos ou categorias, como por exemplo, os invertebrados;

b) ausência de diagnóstico de áreas de reprodução (criadouros) e alimentação de animais, podendo comprometer a viabilidade das populações biológicas atingidas e a avaliação sobre a fauna.
Fairweather $(1989 ; 1994)$ também fez uma análise de estudos de impacto ambiental e, conforme esse autor acrescenta-se à listagem da publicação supracitada as seguintes deficiências:

a) amostragem temporal insuficiente, especialmente se tratando de fauna, deixando de levar em consideração fenômenos reprodutivos, migratórios e comportamentais afetados pelas diferentes épocas do ano;

b) falta de clareza sobre os critérios utilizados para determinar conservação (raridade ou grau de ameaça de uma espécie, potencial de uma área para reabilitação);

c) falta de estudo dos processos ecológicos ocorrentes no ambiente estudado;

d) falta de monitoramento posterior para averiguação se os prognósticos descritos no estudo estavam corretos e se as medidas mitigadoras foram eficazes.

O presente trabalho corrobora as afirmações acima tendo sido identificadas falhas semelhantes nos estudos analisados: (i) ausência da informação sobre invertebrados terrestres, somente fazendo referência a invertebrados aquáticos; (ii) ausência da identificação de áreas de reprodução e alimentação, sendo que somente um estudo apontou áreas utilizadas por peixes como criadouros e áreas essenciais à sobrevivência de 
invertebrados aquáticos; (iii) ausência da identificação ou identificação superficial de fenômenos de migração e aspectos comportamentais, sem análise sazonal; (iv) ausência ou caracterização superficial dos processos e interações ecológicas presentes na área de estudo; (v) ausência da identificação da estrutura das comunidades presentes e espécies-chave importantes para a conservação dessa estrutura; e (vi) ausência da identificação de bioindicadores a serem utilizados como ferramentas nos processos de monitoramento.

O último item citado se torna particularmente alarmante quando cruzado com as medidas mitigadoras apresentadas pelos estudos, indicando a necessidade de monitoramento da fauna. No entanto, nos diagnósticos dos três estudos que indicam o monitoramento como medida mitigadora não há parâmetros para que esse monitoramento seja realizado de maneira adequada. Assim, tanto o diagnóstico anterior à implantação do empreendimento, quanto o monitoramento após o empreendimento instalado são falhos, não podendo ser aplicada a metodologia BACI de identificação de reais impactos ao meio advindos das atividades agora a ele imputadas. Além disso, essa metodologia também não poderia ser aplicada uma vez que não foi prevista a coleta de dados em áreas controle, o que daria um indicativo da variabilidade natural daquele parâmetro, contra a qual a variabilidade identificada antes e depois da instalação do empreendimento seria comparada.

Pela análise dos dados percebe-se que os estudos avaliados apresentam listagem de espécies, mas não suas relações, distribuição, abundância e as espécieschave. Estudos das espécies de maneira isolada não levam ao conhecimento dos processos ecológicos da comunidade estudada, pois estudos quantitativos devem ser acompanhados de estudos qualitativos. Deve-se considerar também que nem sempre as espécies mais abundantes são as mais importantes na estrutura de uma comunidade (LANA, 2003).

Mesmo o grupo "aves", sabidamente representativo do estado de conservação dos habitats e que possui espécies de fácil identificação (SÁNCHEZ, 2006), somente foi apresentado nos EIAs avaliados de maneira descritiva (isto é, numa lista de espécies) sem análises de abundância ou distribuição que pudesse ser relacionada com o meio ou com o empreendimento proposto.

Sutherland (1995) chama a atenção para o fato de que muitas espécies, em especial os invertebrados, têm diferentes necessidades nas diferentes fases de vida. Essas constatações levam a conclusão de que, ao estudar uma comunidade de uma determinada área, uma simples lista de espécies encontradas, ainda que inclua invertebrados, não transmitiria a complexidade ecológica existente naquele local, assim como não forneceria subsídios para a definição de medidas de conservação dessas espécies.

O mesmo autor apresenta o exemplo de um invertebrado polinizador, demonstrando que se suas necessidades ecológicas (para abrigo, reprodução, alimentação) não forem supridas, ele deixará de realizar o serviço de transporte de pólen, colocando em risco a viabilidade de uma segunda espécie (a planta, por exemplo), que por sua vez poderá afetar a existência de outras espécies. Assim, a ecologia de uma espécie depende da inter-relação de uma série de outras espécies. É importante que os estudos de impacto ambiental apresentem, além da lista de espécies existentes (número de espécies), a estrutura florística da área e seu entorno e a abundância relativa das espécies (SUTHERLAND, 1995). Esses dados permitiriam estabelecer as relações ecológicas mais relevantes e que devem ser preservadas. Ressalta-se ainda que a comunidade existente em uma área é fortemente influenciada por fatores físicos e essa relação também deve ser levada em consideração a fim de indicar medidas de conservação.

Ao não levar em consideração espécies de nível trófico inferiores, ou de grupos como invertebrados, um estudo pode falhar na identificação de espécies-chave que têm uma grande capacidade de afetar a diversidade e abundância das demais dentro de uma comunidade e ecossistema (LANA, 2003). Considerando-se que os invertebrados correspondem a cerca de $95 \%$ de todo o Reino Animal (BARNES, 1984), a não inclusão desse grupo nos diagnósticos é uma omissão importante. Essa deficiência provavelmente é refletida também em outros grupos de seres vivos normalmente não tratados por estudos de impacto ambiental como os do Reino Monera (bactérias e algas azuis), Protista (protozoários), 
Fungi (fungos) (seguindo o sistema de cinco reinos CAMPBELL, 1996). Assim, os EIAs desconsideram essas formas de vida como possíveis receptoras dos impactos gerados pelos empreendimentos analisados, desconsiderando também sua influência na estrutura da comunidade.

Os estudos setoriais completos - meio físico, meio biótico, meio sócio-econômico - também devem ser integrados entre si, para que seja possível a descrição das interações ecológicas. Por exemplo, segundo Lana (2003), a correlação da poluição e valores de biodiversidade pode ser uma importante ferramenta biológica para avaliar o grau de pertubação de um ambiente.

Com relação à riqueza e abundância das espécies, existem índices de diversidade descritos e utilizados na literatura (ex: Índice de Simpson e Índice de Shannon-Wiener), que poderiam ser utilizados em estudos de impacto ambiental. Ainda que esses índices isoladamente não levem a um entendimento completo da diversidade de uma comunidade (LANA, 2003), eles podem ser úteis, mas raramente são utilizados como ferramentas de descrição e análise da estrutura das comunidades. Por exemplo, em um recente Termo de Referência elaborado para loteamento na localidade de Jurerê, em Florianópolis, SC, as seguintes análises foram solicitadas: "[...] à descrição das interações ecológicas existentes deverão ser acrescidos índices que permitam a avaliação das condições ambientais atuais e das modificações sofridas pelo ambiente ao longo do tempo, permitindo assim o entendimento da dinâmica dos ecossistemas locais".

Algumas carências dos estudos ambientais são decorrentes da falta de exigências por parte da legislação e dos órgãos públicos de meio ambiente. Ainda que existam documentos que expressamente definam parâmetros para caracterização dos ambientes (SUREHMA; GTZ, 1992), ${ }^{1}$ a Resolução CONAMA

\footnotetext{
Manual de Avaliação de Impactos Ambientais que na definição dos parâmetros para ecossistemas terrestres inclui identificação de espécies vegetais para a determinação da qualidade do ar, umidade e perturbação do solo; descrição das inter-relações fauna-fauna e fauna-flora; mapeamento das fontes de alimentação e dessedentação, abrigo e
}

001/86 que guia os estudos de impacto ambiental cita, mas não salienta, a importância de uma abordagem mais abrangente e que leve em consideração as características ecológicas da área. Vale lembrar que a mencionada resolução é o principal documento que estabelece as diretrizes dos estudos de impacto ambiental.

No entanto, outras razões para as deficiências detectadas advêm de fatores como: recursos limitados para desenvolver o estudo - tempo, equipe e recursos financeiros; falha nos termos de referência que guiarão os estudos e sua análise; técnicos com pouco preparo, tanto do órgão ambiental que analisará o estudo, quanto da equipe contratada para o estudo; pressão do empreendedor sobre a equipe contratada para que o estudo seja feito sem muita profundidade, em tempo exíguo e a um custo baixo; entre outros fatores.

Independentemente das causas, os resultados encontrados indicam que os EIA/RIMAs não são satisfatórios e infere-se que os estudos avaliados não fazem as análises necessárias para um adequado entendimento do ambiente estudado. Assim, os dados obtidos nesse estudo corroboram as hipóteses propostas de que as informações produzidas nos estudos de impacto ambiental, a fim de balizar processos de licenciamento, não são suficientes para subsidiar decisões que permitam mais eficiência no objetivo de conservação dos ambientes naturais e suas comunidades.

De acordo com a análise aqui realizada, conclui-se que a os estudos de impacto ambiental tipicamente não realizam um diagnóstico do meio biótico suficientemente detalhado para subsidiar a posterior avaliação de impactos e que a avaliação de impactos ambientais não relaciona as interações ecológicas com as intervenções humanas resultantes do empreendimento/atividade proposto.

Dessa forma, recomenda-se que na equipe encarregada da elaboração dos termos de referência sejam incluídos profissionais com reconhecida capacitação na ciência ecológica, de maneira a tornar esses documentos mais abrangentes e que levem a estudos eficazes.

áreas territoriais para a fauna; áreas para reprodução e desenvolvimento das crias, assim como fonte de materiais para ninhos; entre outros. 
Adicionalmente, recomenda-se também que órgãos públicos envolvidos com a análise dos estudos e com o licenciamento de empreendimentos se tornem mais exigentes em matéria ecológica. Uma vez que os estudos ambientais são peças essenciais nos processos decisórios, o tratamento dos aspectos ecológicos a partir de uma ótica científica e atualizada poderá contribuir de maneira importante para a preservação dos ambientes e dos recursos naturais.

\section{Agradecimentos}

Agradeço à Biblioteca da Fundação de Meio Ambiente de SC (FATMA) pela disponibilização dos estudos, aos colegas da Universidade de Santa Catarina e Universidade Federal do Paraná, pela leitura, críticas e contribuições, e a todos os colegas que dividiram comigo suas experiências em estudos de impacto ambiental.

\section{Referências}

ASSIS, C.; TOLEDO, C. B.; ROMANIUC NETO, S.; CORDEIRO, I. Nossas Plantas: Mata Atlântica. São Paulo: Editora FTD, 1994. $73 \mathrm{p}$.

BARNES, R. D. Zoologia dos Invertebrados. 4. ed. São Paulo: Livraria Roca, 1984. 1179 p.

BARROS, F. Ghost crabs as a tool for rapid assessment of human impacts on exposed sandy beaches. Biological Conservation, Boston, v. 97, p. 399-404, 2001.

BLANKENSTEYN, A. O uso do caranguejo maria-farinha Ocypode quadrata (Fabricius, 1787) (Crustacea: Ocypodidae) como indicador de impactos antropogênicos em praias arenosas da Ilha de Santa Catarina, SC. Revista Brasileira de Zoologia, Curitiba, v. 23, p. 870-876, 2006.

BRASIL. Ministério Público da União. Ministério Público Federal. 4a Câmara de Coordenação e Revisão. Escola Superior do Ministério Público da União. Deficiências em Estudos de Impacto Ambiental: síntese de uma experiência. Brasília: ESMPU, 2004. 48 p.

CAMPBELL, N. A. Biology. 4. ed. San Francisco: The Benjamin/ Cummings Publishing Company, 1996. 1205 p.

CICIN-SAIN, B. Sustainable development and integrated coastal management. Ocean \& Coastal Management, Augustinusga, v. 21, p. 11-43, 1993.

FAIRWEATHER, P. G. Environmental impact assessment. Where is the science in EIA? Search, Sidney, v. 20, n. 5, p. 141-144, 1989. FAIRWEATHER, P. G. Improving the use of science in environmental assessments. Australian Zoologist, Sidney, v. 29, p. 3-4, 1994.

HOCKEY, P. A. R.; CURTIS, O. E. Use of basic biological information for rapid prediction of the response of species to habitat loss. Conservation Biology, San Francisco, v. 23, n. 1, p. 64-71, 2009.

KAY, R.; ALDER, J. Coastal Planning and Management. New York: E \& FN SPON - Routledge, 1999. 375 p.

KREBS, C. J. Ecology: the experimental analysis of distribution and abundance. 3. ed. New York: Hasper International Edition, 1985. $800 \mathrm{p}$.

LANA, P. da C. O Valor da biodiversidade e o impasse taxonômico: diversidade marinha como estudo de caso. Desenvolvimento e Meio Ambiente, Curitiba, v. 8, p. 97-104, 2003.

MOTA, S. Urbanização e Meio Ambiente. 3. ed. Rio de Janeiro: ABES, 2003. 356 p.

NEVES, F. M.; BEMVENUTI, C. E. The ghost crab Ocypode quadrata (Fabricius, 1787) as a potential indicator of anthropic impact along the Rio Grande do Sul coast, Brazil. Biological Conservation, Boston, v. 133, p. 431-435, 2006.

ODUM, E. P. Ecologia. Rio de Janeiro: Editora Guanabara Koogan S.A., 1988. 434 p.

PETRUCIO, M. M.; MEDEIROS, A. O.; ROSA, C. A.; BARBOSA, F. A. R. Trophic state and microorganisms community of major subbasins of the Middle Rio Doce Basin, Southeast Brazil. Brazilian Archives of Biology and Technology, Curitiba, v. 48, n. 4, p. 625633, 2005.

PULlin, A. S. Conservation Biology. Cambridge: Cambridge University Press, 2004. 345 p.

RIBEIRO, M. C.; METZGeR, J. P.; MARTENSEN, A. C.; PONZONI, F. J; HIROTA M. M. The Brazilian Atlantic Forest: How much is left, and how is the remaining forest distributed? Implications for conservation. Biological Conservation, Boston, v. 142, n. 6, p. 1141-1153, 2009.

SACHS, I. Ecodesenvolvimento: crescer sem destruir. São Paulo: Editora Vértice, 1986. 207 p.

SANFORD, M. P.; MANLEY, P. N.; MURPHY, D. D. Effects of urban development on ant communities implications for ecosystem services and management. Conservation Biology, San Francisco, v. 23, n. 1, p. 131-141, 2009.

SÁNCHEZ, L. H. Avaliação de Impacto Ambiental: conceitos e métodos. São Paulo: Oficina de Textos, 2006. 495 p.

SCHERER, M. E. G. La influencia de la gestión costera en la conservación de los ecosistemas. Énfasis en la isla de Santa Catarina - Brasil. 2001. 547 f. Tese (Doutorado em Ciências do Mar) - Universidade de Cádiz, Cádiz. 2001.

SUREHMA - SUPERINTENDÊNCIA DOS RECURSOS HÍDRICOS E DE MEIO AMBIENTE; GTZ - DEUTSCHE GESELLSHAFT FÜR TECHNISCHE ZUSAMMENARBEIT. MAIA - Manual de Avaliação de Impactos Ambientais. Curitiba: Estado do Paraná, 1992.

SUTHERLAND, W. J. Introduction and principles of Ecological Management. Managing Habitats for Conservation. London: Cambridge University Press, 1995. 399 p.

TOWSEND, C. R.; BEGON, M.; HARPER, J. L. Fundamentos em Ecologia. 2. ed. Porto Alegre: Editora Artmed, 2006. 592 p.

UNDERWOOD, A. J.; CHAPMAN, M. G. Coastal marine ecology of temperate Australia. Sydney: University of New South Wales Press Ltda, 1995. 342 p. 